\title{
Resource Description and Access Adoption and Implementation in Public Libraries in the United States
}

\section{Roman S. Panchyshyn, Frank P. Lambert, and Sevim McCutcheon}

This study surveyed the current state of knowledge about, and application or use of, Resource Description and Access (RDA) among American public library catalogers. In 2017, an online survey request was e-mailed to four thousand libraries for the person or persons most responsible for cataloging to complete the questionnaire. More than three hundred libraries responded. The data expose serious concerns with RDA adoption within the public library sector. While a majority of catalogers know about RDA, their working knowledge about it differs substantially depending on whether they work in rural or urban library settings. Regardless, 22 percent of respondants still had not heard of the RDA standard until completing this survey. While further training and educational opportunities (along with funds) for catalogers nationwide would help minimize this disparity, LIS schools also can play a role by educating more thoroughly the next generations of catalogers in this newer descriptive standard. Coming on the brink of a shift in the theoretical framework of the RDA standard, from the Functional Requirements for Bibliographic Records (FRBR) model to the IFLA Library Reference Model (LRM), public library catalogers risk falling even farther behind in their knowledge and competency with the RDA standard.

Roman S. Panchyshyn (rpanchys@ kent.edu) is Head of Cataloging and an Associate Professor, Metadata and Catalog Department, Kent State University Libraries. Frank P. Lambert (Frank.Lambert@MTSU.edu) is an Assistant Professor and Program Coordinator Master of Library Science Program, Womack Educational Leadership Department, College of Education, Middle Tennessee State University. Sevim McCutcheon (Lmccutch@kent. edu) is a Catalog Librarian and Associate Professor, Metadata and Catalog Department, Kent State University Libraries.

Manuscript submitted March 5, 2018; returned to authors for revision May 9. 2018; revised manuscript submitted July 3, 2018; accepted for publication August 31, 2018.
T $\mathrm{n}$ 2013, a paradigm shift occurred in the cataloging landscape. After extensive 1 testing and review, Resource Description and Access (RDA) was adopted by the three US national libraries (Library of Congress (LC), the National Library of Medicine (NLM), and the National Agricultural Library (NAL)). Other major research libraries, both in the United States and internationally, followed suit. RDA replaced the Anglo-American Cataloguing Rules 2nd Edition (AACR2) published in 1978 and implemented in 1981. ${ }^{1}$ In anticipation of the switch, many libraries began preparing their staff for RDA implementation by reviewing available training options. This paper focuses on RDA preparation and adoption in public libraries in the United States.

Lambert, Panchyshyn, and McCutcheon conducted a pilot study on RDA adoption and implementation in 2013 by public libraries in Ohio. They published their findings in a research paper titled "Resource Description and Access and Ohio Public Libraries." The study examined the preparedness and education of public library cataloging staff regarding RDA training and implementation in 
Ohio public libraries. The authors attempted to determine to what extent public library catalogers were receiving the training necessary for successful adoption of RDA. The study noted regional variations among public library staff regarding their extent and exposure to RDA training. It identified regional variations in the level of training needed by public library catalogers, with the greatest need for training occurring among libraries with funding and budget constraints. Additionally, it supported the view that Ohio's public library catalogers lacked the same level of training and comprehension of the RDA standard as academic librarians, especially concerning RDA's theoretical FRBR structure. ${ }^{3}$

By 2017, RDA was implemented by a majority of the major US research and academic libraries. Since the library profession has had time to consider the implications of adopting and implementing RDA, the authors wanted to examine how RDA adoption and training has filtered down to catalogers working in public libraries across the US during this period. Public library catalogers are underrepresented in the library literature, and the 2013 study hinted that their level of education and training was a significant factor in RDA adoption. Their catalog users also were impacted by RDA adoption because the use of RDA data by integrated library systems and discovery layers has changed how they view and use cataloging data.

A significant change to the theoretical framework of the RDA standard is on the horizon. The conceptual models developed by the International Federation of Libraries Associations and Institutions (IFLA), Functional Requirements for Bibliographic Records (FRBR), Functional Requirements for Authority Data (FRAD), and Functional Requirements for Subject Authority Data (FRSAD) will be consolidated and replaced with the Library Reference Model (LRM). ${ }^{4}$ Implementation is planned for summer 2018. While this change may lack the dramatic impact of RDA adoption in 2013, catalogers, both academic and public, will need to understand this new theoretical framework because it will have an impact on their use of the standard.

\section{Purpose Statement}

The purpose of this current study is to determine to what extent RDA adoption and training is filtering down to catalogers in public libraries on a national scale. Using survey methodology, questions posed to participants focused on collecting data on variables such as geographic location, educational level, training history and needs, library size, and budgets. The intent is to obtain an overall perspective on RDA knowledge and adoption among public library catalogers, and to identify what levels of assistance or training may be required to help these catalogers better understand $\mathrm{RDA}$, and to become more effective in their work.

\section{Literature Review}

The literature review examines several recent studies on RDA implementation and training by individual libraries. It also surveys literature dealing with catalogers' levels of education and the rural/urban divide of public library staff. As part of the implementation process, RDA training for staff plays a key role in the transition. The case studies found on RDA implementation and training deal chiefly with academic libraries but have relevance for public library cataloging. Outside of the 2013 paper by Lambert, Panchyshyn, and McCutcheon, no studies focusing directly on RDA education and training for public libraries were located.

Cataloger education and training was identified as a necessary component of successful RDA implementations. Sanner conducted a survey of academic library cataloging administrators immediately before LC's adoption of RDA. ${ }^{5}$ The survey focused on preliminary training for cataloging staff. Sanner identified a distinction between training conducted for cataloging staff and administrators. Administrators were exposed more to RDA's philosophical concepts, while staff were exposed more to differences from previous rules. The differentiation between theory and practicality can apply to both public library staff and to academic library staff. Additionally, providing access to in-house RDA training in the library raises what Sanner calls a "mental shift," or awareness, about RDA.

Hanford discussed RDA training and implementation at Central Connecticut State University (CCSU). ${ }^{6}$ The training aspect of CCSU's RDA implementation was complicated by the fact that staff reductions due to budget cuts and retirements were occurring simultaneously. The remaining staff lacked time to participate in formal training. CCSU used a combination of self-instruction and participation in a training funnel organized by the Online Audio/Visual Catalogers (OLAC) to provide a sizeable portion of their education and training.

Jin and Sandberg's study addresses RDA implementation and training at the University of Illinois Urbana Champaign (UIUC). ${ }^{7}$ UIUC had a sizeable cataloging staff who required instruction. They established an RDA training task force that divided the instruction process into these categories: FRBR overview, RDA monographic, RDA Toolkit, RDA original cataloging training, and RDA training for public services staff. Specific programs targeted selective groups of staff, but the FRBR overview was provided to the entire staff. Education for public services staff included reference librarians and subject specialists. Instruction from the other categories was provided to both original and copy catalogers.

Turner's study reviews RDA training and implementation at Duke University Libraries. ${ }^{8}$ One of the issues Turner focused on was the amount of time required for training. 
Duke made a conscious effort to use online training materials and emphasized hands-on learning over classroom work to reduce instruction time. Duke's implementation group recommended placing emphasis on catalogers' responsibility for ongoing self-study over classroom instruction.

Training costs are equally as important as training time in RDA implementation. Finch addressed the issue of RDA training and education for small to medium-sized academic libraries based on Oakland University's (OU) RDA implementation. ${ }^{9}$ Finch points out that RDA training at smaller institutions lagged behind large research universities because of a disparity in resources. In-house training, a hybrid of both online and in-person, based on adult learning theories, became OU's approach. They developed a six-week training course based on freely available RDA training materials that were accessible on the internet. All library faculty and staff received invitations to participate. OU found this approach to be an effective and affordable solution, especially for libraries operating with tight budgets.

Academic librarians conducted several research surveys on RDA implementation following LC's formal adoption of RDA. Some of these surveys included requests for information on RDA education and training. Park and Tosaka conducted an email interview survey of RDA implementation and training issues across US academic libraries. ${ }^{10}$ They segregated their data by participants working in large academic libraries and those working at four-year colleges and universities. The survey found that individuals at the large academics benefitted more from workshops, webinars, and local training opportunities. Many of the large academics also had RDA experts on staff to assist with training. The other group relied mostly on webinars and individual self-paced online learning materials such as those freely accessible through LC. Overall, the smaller academics implemented RDA without much training. Additionally, when survey participants were asked how RDA would impact the role of the cataloger in the future, some respondents expressed concern about the divide between those libraries that can afford the resources and support to transition to RDA and those that cannot. Park and Tosaka point out that the new cataloging code could disadvantage a much larger pool of public and school libraries, as well as small academic libraries, which cannot afford the transition costs.

Haider published an extensive survey of RDA use and cataloging practices by fifty-nine academic libraries. ${ }^{11} \mathrm{He}$ asked how much these libraries spent on seminars, webinars, classes, books, courses, other educational resources, and conferences addressing RDA in the last year. The mean for educational spending (excluding conferences) was $\$ 639.12$ per person. For conferences, mean spending was $\$ 175.58$ per person. In each case, private colleges spent more on average. Haider also posed a question addressing how much libraries have continued to spend on cataloging over the last five years. In their responses, 35.59 percent of the libraries stated that they had spent "about the same," while 32.20 percent stated that they have spent "somewhat less." Only 8.47 percent stated that they have spent "somewhat more." These categories are loosely defined, but the trend for spending less for cataloging with RDA is evident.

There is literature about RDA implementation in Canada that has bearing on public libraries. Cross et al. conducted a survey in 2013 of RDA implementation in Canadian libraries, which included public libraries. ${ }^{12}$ For English-speaking public libraries, the survey reported partial adoption of RDA at 58.5 percent, non-adoption at 35.3 percent, and full adoption at 5.9 percent. Canadian public libraries serving French-speaking populations faced a different challenge. The RDA code was not available in French until 2013, several years after the first English publication in 2010. Staff preparation and training for French-speaking librarians was compressed into a much shorter period. However, statistics by the library sector revealed that for public libraries, French-speaking libraries had the highest staff participation from all sectors (169 participants).

This section of the literature review covers data available on the rural-urban divide of public libraries and with public library staffing. There are statistical tools available that can provide demographic information for US public libraries. The most complete source for statistics is the Public Libraries Survey, which has been conducted annually by the Institute of Museum and Library Services (IMLS) since $1988 .^{13}$ The data, which are available freely, includes information about library visits, circulation, population served, size of collections, public service hours, staffing, electronic resources, operating revenues and expenditures, and number of service outlets. Users can segregate data nationally, by state, and by individual libraries.

PLAmetrics, a commercial database service, combines the IMLS data with data from its own annual Public Library Data Service (PLDS) survey. ${ }^{14}$ The PLDS survey gathers information from public libraries across the US and Canada and presents topical data on finances, library resources, annual use figures, and technology. PLDS also publishes an annual report, Characteristics and Trends, which highlights trends found in the data and is available at no cost. ${ }^{15}$

Both of these databases can be mined for information on the educational level of staff in public libraries. The data are not granular to the extent that it identifies all the staff responsible for cataloging in public libraries, but several trends do emerge. Between FY2012 and FY2016, the rate of increase nationally of MLS librarians is 0.54 percent, while the rate of increase of non-MLS librarians is 3.24 percent. Other staff has shown a rate decrease of 1.42 percent. ${ }^{16}$ The trend shows there is a significant increase in the number of non-degreed librarians staffing public libraries. 
Real, Bertot, and Jaeger studied rural public libraries from the perspective of digital inclusion. ${ }^{17}$ Data from their study touched upon the rural/urban divide of public libraries. Using the criteria that a public library is considered to be rural if its population or legal service area has a population of 25,000 or less, the data showed that rural public libraries:

- have on average less than one (.75) librarian with a master's degree from an ALA accredited Institution;

- have an average of 1.9 librarians, defined as an employee holding the title of librarian;

- have an average total of 4.0 staff, including both fulland part-time employees;

- have a median annual income (from all sources) of $\$ 118,704.50$;

- have an average of 41,425 visits annually; and

- typically have one building or branch that is open an average of 40 hours/week.

The presence of cataloging staff in public libraries does not come to the forefront when staffing models are examined. Goodrich examined data from a Public Library Association (PLA) Workload Measures and Staffing Patterns Committee survey to investigate how public libraries make staffing allocation decisions. ${ }^{18}$ The two major factors that influenced public library staffing were the number of hours required for opening and the times when the heaviest volume of patron traffic was to be expected. Goodrich also points out the impact that political factors (levies and budgets) have on library staffing.

Managers of rural public libraries face significant hiring and staffing challenges, which is a contributing factor to the rural-urban divide. In an overview of small public library staffing, Bliss notes that even at the rural level, technical training needs to be provided to improve the skills of library staff. ${ }^{19}$ There are many continuing education programs available for enhancing cataloging skills but finding cost-effective programs that serve both the interests of the library and the individual staff member can be challenging. This has an impact on the ability of public library staff to obtain training in the RDA standard, especially if this training has a low priority.

Another factor that needs to be considered is that many public libraries have banded together into consortia. This allows them to centralize cataloging and processing in a more cost-effective manner. Stumpf conducted a case study dealing with the Municipal Library Consortium (MLC) of St. Louis County, a group of eight independent public libraries in Missouri, which reinforced this position. ${ }^{20}$ In 2013, OCLC published a document titled "A Snapshot of Priorities and Perspectives: U.S. Library Consortia," which was based on a response of 101 consortia that responded to their survey. ${ }^{21}$ The data shows that 52 percent of these consortia include multiple types of libraries (including public) and that 16 percent were for public libraries only. This is evidence that cataloging skills, and cataloging with RDA, may not be necessary or required at the individual or local library level.

While much of this literature review deals specifically with academic libraries, it supports some of the trends and issues that the authors discovered in their Ohio 2013 study of public libraries. Lack of funding and access to resources can be a barrier. There is evidence that some cataloging staff in public libraries have adopted a "learn-as-you-go" approach, working with RDA with very little formal training. This is supplemented by using free online documentation for training, if available. Other libraries do not bother or care about RDA training. There is also a gap in the literature about the impact that RDA implementation is having on public library users. Burris points out that technical services is just as integral to the user experience in public libraries as is public services, especially when dealing with emerging technologies. ${ }^{22}$ RDA implementation, along with the potential offered by newly developing linked data systems, is going to have a major impact on user perceptions and experiences in public libraries.

\section{Research Problem and Questions}

Like the authors' original paper, we seek to understand better, and thus communicate that understanding to our readers, the challenges that public libraries may encounter and attempt to resolve while implementing into regular practice libraries' most recent version of RDA. The current paper differs substantially from the 2013 paper. The authors expanded their inquiry from one state to survey public libraries in all fifty states. Potential participants were asked more questions than those who participated in the authors' earlier effort because of "lessons learned" from their original pilot study focusing on just one state. To accomplish this more expansive research task, the authors attempt to provide sufficient data and analyses to respond adequately to the following research questions:

How prepared are US public library catalogers for RDA implementation? For those public libraries already using RDA, what factors affect catalogers' use of RDA? More specifically, they attempted to address empirically the following: What is the nature of the knowledge/lack of knowledge among American public library catalogers concerning RDA, and, to what extent do demographic and other independent variables affect such knowledge? 


\section{Limitations of the Study}

Despite the authors' best efforts to design a comprehensive survey in a simple and easy to complete format, the survey response rate was quite low. While this may be due to a number of factors, including possible "survey fatigue," one issue that affected the response rate particularly was an inability to acquire accurate email addresses from one primary, authoritative resource of public library directors and/or managers to whom the authors could send an invitation to participate. Of 4,163 libraries or library systems identified, 673 email invitations were "bounced back" to the authors' Qualtrics survey software after the initial invitations were sent. Due to the highly transitory movement of library directors and managers, many email addresses may have become obsolete without the authors' knowledge, a sampling issue that can occur regardless of the sources used to compile a sample population. Although the authors' survey has revealed interesting data concerning RDA's adoption in US public libraries, the relatively small set of responses from their original population list of email addresses require that the authors as researchers not overgeneralize or infer too much in their findings. However, even with a 100 percent response rate, there is always error involved in quantitative social sciences research. Despite this, their survey collected sufficient data to give most of their statistical tests enough power to discover interesting differences and associations between variables and gathered rather substantial, interesting qualitative data. The combination of quantitative and qualitative data presented below provides a more complete picture of public libraries' challenges and successes with RDA implementation.

\section{Method and Sampling}

The questionnaire design used for this current study was based primarily on the authors' earlier Ohio study, although additional variables and modifications were included in this version. When the questionnaire was completed, two public library staff members were invited to pre-test the survey and its questionnaire. Their feedback was incorporated into the final version. The authors also obtained contact information for all American public library directors from state library websites that, in the majority of cases, included a list of the respective state's public libraries. The information from these pages included the directors' names, email addresses, and other contact information. This information was recorded in an Excel spreadsheet that was uploaded to Qualtrics to distribute the survey invitation. If a particular state library website lacked a comprehensive list of public libraries and/or library systems with requisite contact information, every public library's contact information within that state was searched through online directories such as LibWeb (http://www.lib-web.org/united-states/public -libraries), with the needed information being added to the same Excel spreadsheet. At the end of this exercise, 4,163 individual libraries or library systems across the US were identified. Survey invitations were emailed to the directors of these libraries/library systems on March 17, 2017, with a follow up invitation sent on April 3, 2017, requesting that the director forward the survey invitation to the respective library system's main cataloger. "Main cataloger" was defined as the person who performed or supervised most of the cataloging for the library/library system, regardless of job title or educational level (paraprofessional or a librarian with a master's in library science). At the close of this survey on April 10, 2017, the authors received 310 valid questionnaires out of 320 (ten of whom submitted a blank survey), a 7.4 percent response rate (8.9 percent not including the invitations "bounced" back to Qualtrics). With this response rate, the authors may be 95 percent confident that their inferences used for their survey data have an accuracy interval of +/- 5.36 percent. The survey and all associated materials received approval from Kent State University's Institutional Review Board prior to data collection. Since virtually all questionnaire variables were either nominal or ordinal scales of measurement, all inferential tests performed using SPSS software to test hypotheses were non-parametric.

The questionnaire (see appendix) asked respondents to identify the respective state in which they worked. Unfortunately, due to the low response rate and not receiving public library cataloger responses from all states, the validity of statistical tests such as Chi Square was negatively impacted concerning this variable (state where library system located). To correct invalid Chi Square calculations due to more than 20 percent of cells within crosstabs having expected counts of less than five, individual states were combined into their respective Census Bureau regions. Thus, the analysis and discussion focus on the regions, if warranted, rather on the individual states. Table 1 shows the states and their respective Census Bureau regions. ${ }^{23}$ Public libraries/ library systems from forty states responded. Most responses were from Texas $(n=29)$. Public libraries/library systems in the Northeast Census Bureau region are represented least in the survey as only 10 percent of returned questionnaires were from that region.

\section{Findings}

Four years after LC's full RDA adoption, public libraries appear to be very much in a period of transition. While 17.7 percent of respondents reported that they still use AACR2 in different formats and ways (see figure 1) and 20.2 percent report that they now use RDA, a strong plurality (48.9 
Table 1. States and Census Bureau Regions. States with non-responding library systems/ libraries marked $(x)$

\begin{tabular}{llll}
\hline Region 1: Northeast & Region 2: Midwest & Region 3: South & Region 4: West \\
Connecticut-x & Illinois & Delaware & Arizona \\
Maine & Indiana & Florida & Colorado-x \\
Massachusetts-x & Michigan & Georgia & Idaho \\
New Hampshire-x & Ohio & Maryland & Montana \\
Rhode Island-x & Wisconsin & North Carolina & Nevada \\
Vermont & Iowa-x & South Carolina-x & New Mexico \\
New Jersey & Kansas & Virginia & Utah-x \\
New York & Minnesota & West Virginia & Wyoming \\
Pennsylvania & Missouri & Alabama & Alaska \\
& Nebraska & Kentucky & California \\
& North Dakota & Mississippi & Hawaii-x \\
& South Dakota-x & Tennessee & Oregon \\
& & Arkansas & Washington \\
& & Louisiana & \\
& & Oklahoma & \\
& & Texas & \\
\hline
\end{tabular}

libraries/library systems were significantly less likely to have heard about RDA than were those who worked for libraries in urbanized areas/clusters $\left(X^{2}=19.651, p=0.00\right) ; 12.1$ percent of rural catalogers had not heard of or about RDA versus 2.0 percent of urban catalogers. As a result, these same rural respondents were significantly more likely to be using still the AACR2R or another type of descriptive standard $\left(X^{2}=27.057, p=0.00\right)$, whereas a significantly larger number of urban respondents were using RDA for resource description at the time of this survey. This result may be due partly to the fact that urban catalogers appear to have generally received significantly more training regardless of format (in-person, webinars, etc.) than rural catalogers $\left(X^{2}=30.497, p=0.00\right)$. In fact, 42.9 percent of catalogers who identified that their library fit our definition articulated in our question-

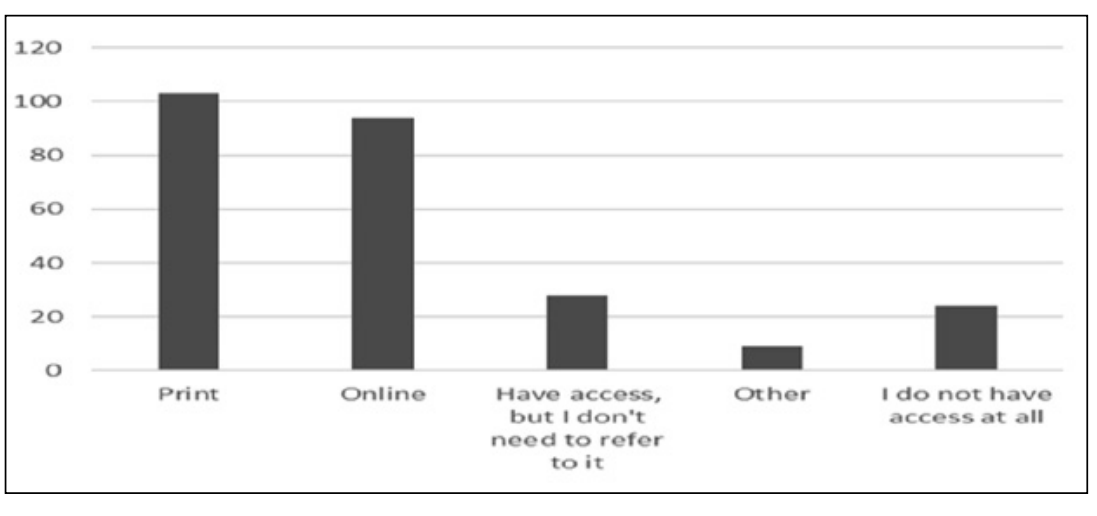

Figure 1. Access to AACR for Libraries Using it Still for Descriptive Purposes naire of "rural" have received zero hours of RDA training. Not surprisingly, a significant number of rural catalogers characterize their knowledge of RDA as "none" or "basic," compared to their urban counterparts whom generally consider their RDA knowledge to be "intermediate" or"advanced" $\left(X^{2}=41.752\right.$. $p=0.00$ ).

Because of the apparent urban/rural divide in knowledge and application of RDA for public library cataloging, further analysis of this particular demographic factor is warranted. A slight majority (51 percent) of survey respondents worked at public libraries/library systems located in areas of the US

percent) report they use a combination of the two standards in regular cataloging practice. A total of 21.6 percent of all respondents heard of RDA for only the first time during the completion of our questionnaire. Although this response is a minority of respondents, a number of other demographic factors appear to have affected this variable, although RDA has been LC's official descriptive standard for the past four years. The respondents' highest level of education appears to be significantly related to this outcome $\left(X^{2}=14.871\right.$, $p<0.01$ ). Respondents who answered affirmatively that this was the first time they had heard of RDA tended not to have a master's degree, with those with either high school, associate's, or bachelor's as the highest level of educational attainment having higher observed than expected counts in the cross tabulations. Additionally, catalogers in rural public that the US Census Bureau defines as "rural." ${ }^{24}$ This equals very closely our participants' response to the total population of the community or communities their respective library systems serve (49.4 percent of library systems serve communities with 25,000 or fewer residents). This nearly identical result of matching between respondents' communities' respective populations with the self-identification of these same communities as being rural leads the authors to be cautiously satisfied with the definitions used in the questionnaire (question 18 in the appended questionnaire). These proportions may appear counterintuitive because the US's population is concentrated in urban areas. However, one library system may serve millions of residents within a relatively small land area that comprises a large proportion of a state's population (e.g., New York Public Libraries). 
Table 2. Distribution of respondents' library systems by community population.

\begin{tabular}{lrcc}
\hline $\begin{array}{l}\text { Community } \\
\text { Population }\end{array}$ & Frequency & Percent & $\begin{array}{c}\text { Cumulative } \\
\text { Percent }\end{array}$ \\
\hline $0-25,000$ & 123 & 49.4 & 49.4 \\
\hline $25,001-50,000$ & 41 & 16.5 & 65.9 \\
\hline $50,001-75,000$ & 15 & 6.0 & 71.9 \\
\hline $75,001-100,000$ & 14 & 5.6 & 77.5 \\
\hline $100,001-250,000$ & 21 & 8.4 & 85.9 \\
\hline $250,001-500,000$ & 13 & 5.3 & 91.2 \\
\hline $500,001-750,000$ & 6 & 2.4 & 93.6 \\
\hline $750,001-1,000,000$ & 5 & 2.0 & 95.6 \\
\hline More than $1,000,000$ & 4 & 1.6 & 97.2 \\
\hline Do not know & 7 & 2.8 & 100.0 \\
\hline Total & 249 & 100.0 & \\
\hline
\end{tabular}

Conversely, a rural county public library system may serve very few persons across several communities spread over a large land area, possibly with only one or very few library branches. We present the distribution of respondents' communities served by their library system by population in table 2.

Notwithstanding that a slight majority of our respondents work in rural public libraries/library systems, the majority of those same respondents who hold a graduate degree, and particularly a master's degree, work in urban public library systems. In fact, whether a public library is defined as being rural or urban appears to be a reliable predictor of whether the respondent is more likely to hold a master's degree. Using Chi Square, we discovered that the respondents' highest attainment of education is significantly related to the type of library in which they work $\left(X^{2}=12.776\right.$, $p=0.01$ ). A higher proportion of respondents from urban/ urbanized cluster population centers where their public libraries are located hold a master's degree than those from rural population centers (71.1 percent of urban respondents versus 49.2 percent of rural respondents). Respondents from rural libraries had higher proportions, holding only bachelor's and associate's degrees, or having a secondary school diploma, than did urban respondents.

The ordinal variable of the respondents' libraries' library systems' total budget for all operations and functions showed a great deal of variability, revealing a bimodal distribution (see table 3). The major modal value of these data is $\$ 0-\$ 250,000$ and the minor mode is "More than $\$ 1,000,000$," but the median value is $\$ 500,001-\$ 750,000$. Again, the number of responses at what would be the left side of the distribution appears to match to an extent the left side of table 2's distribution, implying that communities with lower populations tend to have library systems with smaller budgets. Due to the non-normal distribution
Table 3. Total budget for all operations and functions of respondents' respective library system.

\begin{tabular}{lccc}
\hline $\begin{array}{l}\text { Library/Library } \\
\text { System Budget }\end{array}$ & Frequency & Percent & $\begin{array}{c}\text { Cumulative } \\
\text { Percent }\end{array}$ \\
\hline$\$ 0-\$ 250,000$ & 90 & 36.3 & 36.3 \\
\hline $250,001-\$ 500,000$ & 28 & 11.3 & 47.6 \\
$\$ 500,001-\$ 750,000$ & 11 & 4.4 & 52.0 \\
\hline $750,001-\$ 1,000,000$ & 17 & 6.9 & 58.9 \\
\hline More than $\$ 1,000,000$ & 65 & 26.2 & 85.1 \\
\hline Do not know & 37 & 14.9 & 100.0 \\
\hline Total & 248 & 100.0 & \\
\hline
\end{tabular}

of the data for these variables, and because these variables are ordinal, the authors may test this hypothesis using the non-parametric Spearman correlation coefficient inferential statistical test $(r h o)$. A moderate correlation and substantial relationship do indeed exist between these two variables that is also highly significant $(r h o=0.639, p=0.00)$. Some may argue that a statistical test does not need to be conducted to arrive at this conclusion, but smaller communities with more finances available for library budgets could easily be at the left side of the distribution in Table 2. Conversely, more populated communities undergoing financial challenges may fall towards the left side of table 3's distribution. While the rho coefficient is quite high, it is still some distance from a perfect correlation $(r h o=1)$, thus demonstrating what should be logical does not always result in absolute fact. Perhaps not surprisingly, a significant relationship exists between whether a library/library system is rural or urban and the size of the library's/library system's budget $\left(X^{2}=68.946, p=0.00\right)$. Far more urban libraries $(45.8$ percent of urban libraries) have budgets over $\$ 1,000,000$, whereas a majority of rural libraries (56.3 percent of rural libraries) have budgets of $\$ 250,000$ or less.

The rural/urban divide between public library catalogers also extends to RDA cataloging policies. Urban public libraries appear to be significantly more likely to have standards or policies established for copy cataloging of RDA records than rural public libraries $\left(X^{2}=16.056, p=0.00\right)$. Although a majority (58.7 percent) of responding rural libraries accept RDA records for copy from a bibliographic utility, urban libraries appear most likely to follow this practice $\left(X^{2}=29.875, p=0.00\right)$ as an even larger majority of urban public libraries (89.3 percent) accept RDA records for copy cataloging. This highly significant result is due largely to 31.7 percent of responding rural catalogers not knowing or being unsure of whether their library/library system follows this practice. The data show that rural public cataloging staff, in comparison to their urban peers, need to improve their knowledge of RDA. They also need a better understanding of their library systems' policies concerning RDA and copy cataloging records. 


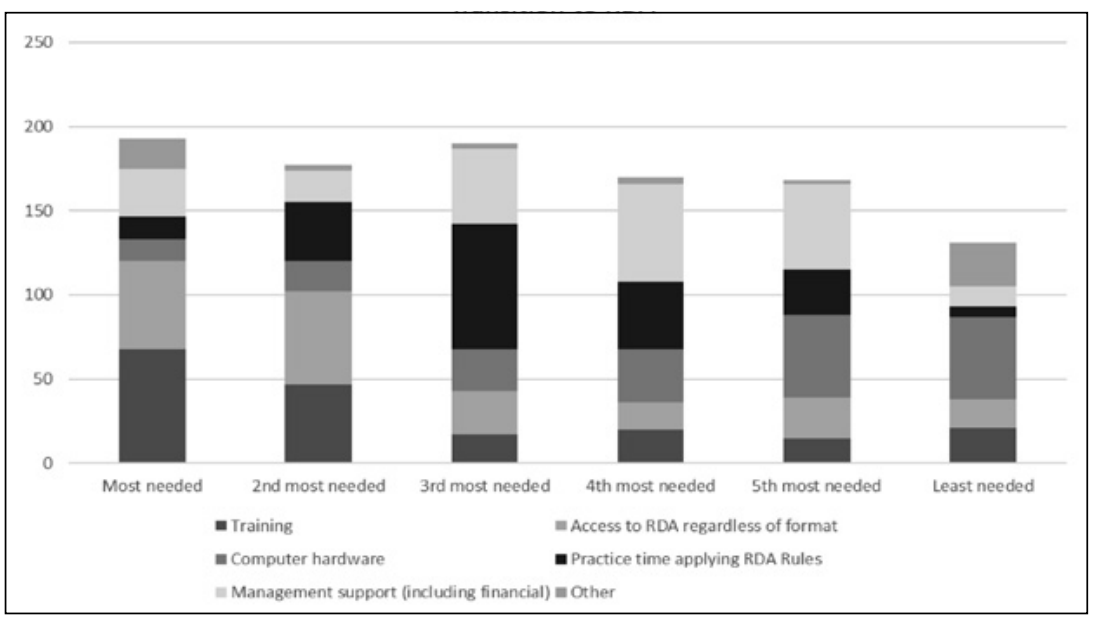

Figure 2. What is Needed Most to Transition to RDA

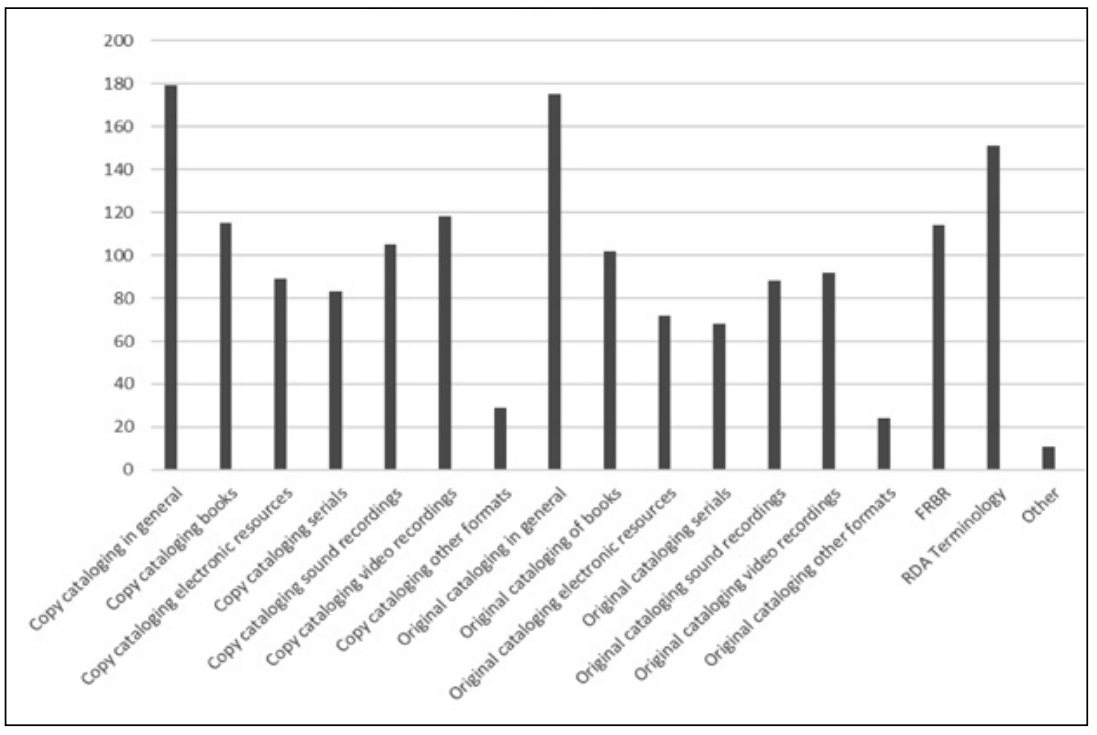

Figure 3. Responses by Cataloging Public Librarians of Type of Training Required in RDA

While certainly not every public library cataloger in the US is likely entirely comfortable with applying RDA, what potential solutions may help these cataloging personnel attain the same level of comfort they might have with AACR? Respondents were asked to rank from the most needed to the least needed, from six predetermined choices, what they perceived to be the most important factor(s) for a smooth transition to RDA. The results in figure 2 show that, by a small margin ( 35.2 percent to 27 percent), RDA training is perceived, perhaps unsurprisingly, by respondents to be what is needed most to transition to the cataloging standard. Access to the RDA Toolkit ranked a strong second as the most needed factor and is clearly (chosen by 31 percent of respondents) the second most needed tool. Once public library catalogers receive training and can access the RDA Toolkit, time to practice applying its rules was clearly the most important (39 percent of respondents) and was the third most needed factor. Management support figures prominently across what is needed most but is regarded as the fourth most needed requirement by a plurality (34.1 percent) of respondents. The need for additional or new equipment for public library catalogers tends to be the least needed requirement to transition to RDA.

Regarding training required for public library catalogers, what in particular do they need? Figure 3 below shows that RDA training for copy and original cataloging in general is needed most, according to respondents. However, greater familiarity with RDA terminology ranked a strong third. Increased knowledge of FRBR also ranks quite highly. Considering that FRBR is RDA's conceptual model, it seems wise for respondents to desire additional training for FRBR and/or possibly LRM.

The rural/urban divide between public library catalogers continues to be demonstrated in the knowledge and understanding of the new language used in RDA. Respondents were asked to record whether they were familiar with these seven terms from FRBR and RDA; element; preferred access point; variant access point; carrier type; manifestation; expression; and work. A highly significant relationship $(p=0.00)$ existed between whether respondents worked in an urban or rural public library system and their familiarity with the seven terms $\left(X^{2}=23.784,16.532,19.777,26.623,29.903\right.$, 25.808 , and 21.118, respectively). Put simply, public library catalogers working for an urban library/library system are statistically more likely to be familiar with those terms than those working in a rural public library/library system. Perhaps not surprisingly, the respondents' level of education played just as significant a role $(p=0.00)$ in this familiarity and knowledge of these same seven terms with those respondents holding a master's degree to be most likely by a considerable margin to being aware of these terms. Much of this gap in knowledge may be mitigated by RDA training and access to RDA as these respondents are likely capable of self-learning.

Who or which institutions are considered best suited to help public library catalogers learn more about RDA? 
Respondents were asked to choose any of the nine options provided in the questionnaire. "National professional library associations" and "Library of Congress" were selected the most, although "Library consortia" ranked quite highly in third place (see figure 4). For each option, respondents were permitted to enter text that specifically mentioned the name of the library consortia, Schools of Library and Information Science (SLIS) of a university, etc., which they would like to see deliver RDA training. The American Library Association (ALA) was listed as the "National professional library association" that most respondents would like to see deliver this training. ALA was listed far more frequently than was any other organization. "Schools of Library and Information

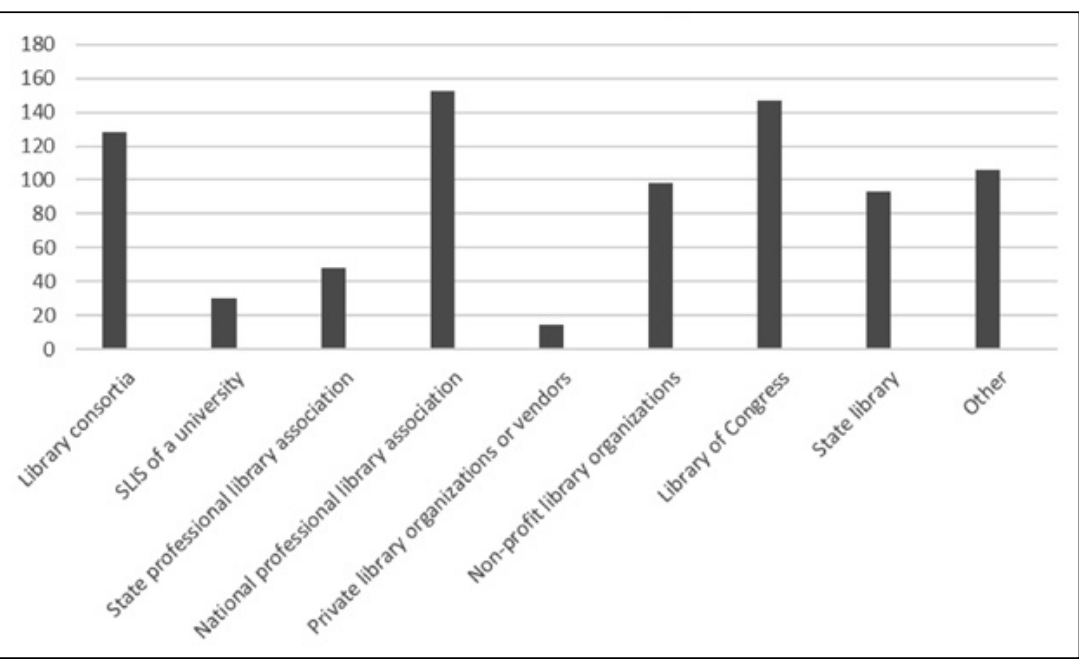

Figure 4. Organizations/Institution that Should Provide RDA Training
Science of a university" was chosen second least of all but elicited the most expressive of responses such as "Absolutely!" or "ALL!!!" While there was no shortage of opinions and suggestions as to which organization(s), other than the respondents' own libraries, should take the lead in providing RDA training, one respondent had an interesting suggestion that he/she articulated after selecting "Other." "Any would be good, but it would be helpful if one specific organization managed the overall training so that it is more consistent (emphasis added)."

There are no statistically significant differences or associations between the Census Bureau Region where the respondents' library system is located and the other variables examined above. This means that where the public library system is physically located in the US (e.g., western US, northeastern US, etc.) has little bearing on RDA adoption and implementation. Thus, the differences and associations reported above between demographic variables appear to be common across the US and not limited to any particular geographic areas.

\section{Qualitative Findings}

Respondents were given the opportunity to "add any other thoughts/comments you might have about RDA adoption, your experience working with it (if applicable), and/or your library's approach to adopting it or not, especially if your thoughts could not be expressed in the [closed-ended] questions above. For example, what are challenges or obstacles to transitioning to RDA? What would help you, your coworkers, and your library make the transition to RDA?" As the study is primarily quantitative, the authors processed all the qualitative responses in an online word cloud application to see what dominant words and terms emerged (see figure 5). ${ }^{25}$ Some of the more dominant words and themes were then searched for in the textual responses for some context where necessary.

To make the image as large as possible for our readers, "RDA" and "cataloging" do not appear in figure 5's image. Both these words and concepts relate directly to the study's purpose. However, RDA is used in reference to both the RDA Toolkit and the print version of the rules. For example, one respondent reports that the obstacles in applying RDA include "...lack of ILS support; cost of accessing RDA rules" and another wrote, "Access to the RDA Toolkit would be very useful for questions as they arise on a regular basis...," possibly meaning that this respondent's library system was unlikely to purchase the Toolkit. It is possible that this is due, as suggested above, to cost. For example, responses included "I do not have access to the actual RDA rules, just other people's interpretation of the rules, due to the cost" and "Ongoing cost of Toolkit seems pretty high and print as currently available is outdated very quickly — this creates a big obstacle for small rural libraries." "Records" is used in context with topics such as the creation and inclusion of AACR2R/RDA hybrid records: ("I catalog in RDA when I receive materials from libraries, and promote 'hybrid' records when other librarians are copy cataloging"; "We made the transition in 2013-we use RDA rules for new records, ILS was 100 percent RDA enriched in 2015, there are still records that could be termed a hybrid of RDA and AACR2 and the role of respective libraries' vendors in creating and supplying RDA bibliographic records ("Bib records were and are converted to RDA by outside vendor (MARCIVE). ILS system not utilizing yet.").

Not surprisingly, "training" also figures prominently, similar to earlier questions to respondents. In the textual responses, "training" was used in context with the lack of financial resources available to train catalogers in RDA 


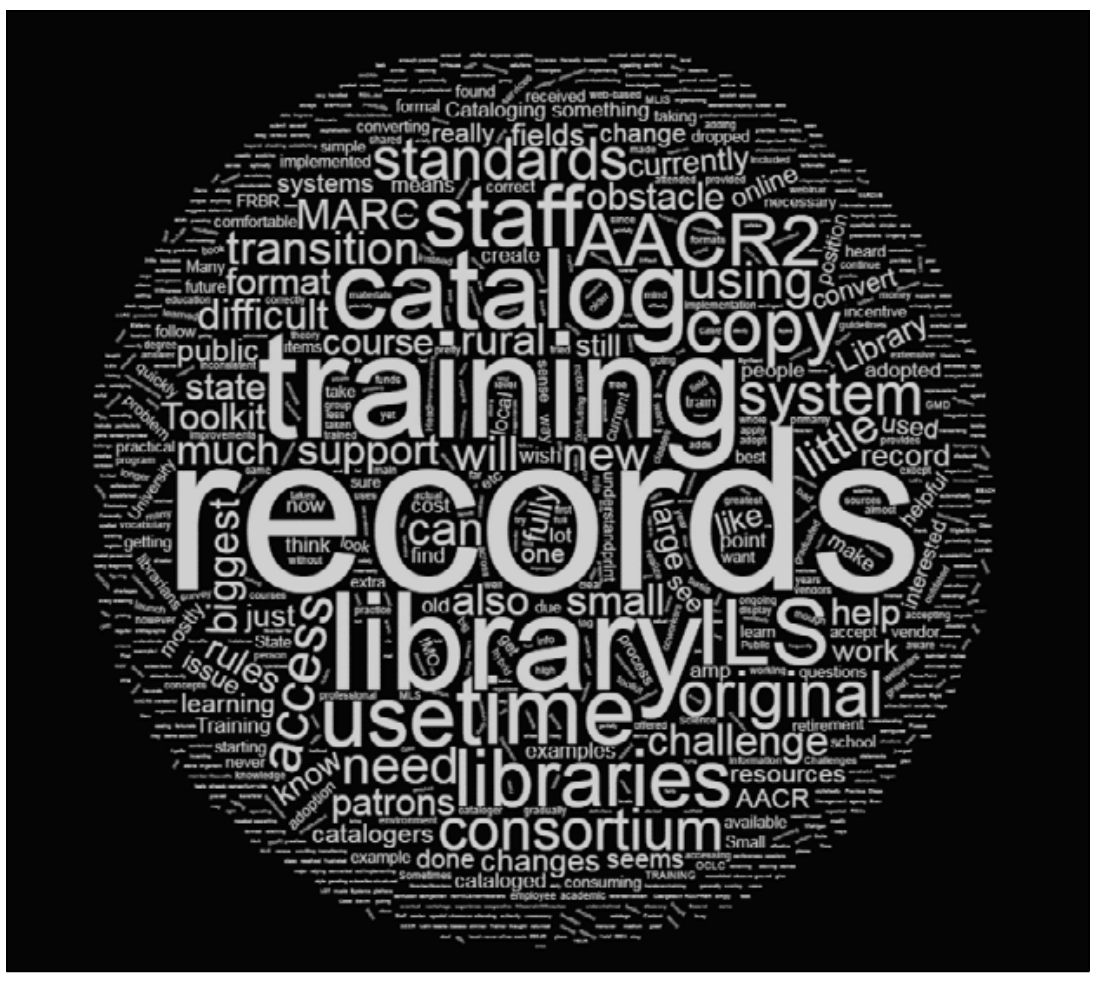

Figure 5. Word Cloud of Qualitative Responses to Survey

the current cataloging system in place," and a respondent from another library wrote, "The main challenge is seeing the need to transition. Since MARC records are not displayed to our patrons, what's the point? To fully transition, we would need to see some actual benefit, either to ourselves (as catalogers) or to our patrons." Whereas some public library catalogers do not appear to see RDA's benefits, another had a balanced perspective of the new cataloging standard: "I can see the benefits of RDA for online resources and large academic institutes (sic), but an AACR3 would have been far more practical for public libraries than RDA. (It also takes an awful lot longer to catalog using it!)."

\section{Discussion}

Undoubtedly, RDA adoption and use in US public libraries is uneven. This unevenness is not found in particular geographic regions across the country; rather, the difference lies most explicitly in whether the library is located in a rural or an urban region. Other

(“Training is the biggest issue at present, which we are in the process of working on. Staff training funds running out towards the end of the fiscal year is also a challenge, as well as the pricing of some online courses"; "No money to convert existing records to RDA records. No money or time for training since all cataloging is done in-house"). However, references to training are not always negative: e.g., "Our state library agency has done a great job in providing training opportunities for cataloging staff in our state. We have access to the RDA Toolkit online as well. Beginning in 2013, RDA training sessions were held in various places in the state" and "Our library system has handled this transition and provides us training and support" are two such illustrative examples. The positive and negative textual responses regarding "training" support the authors' quantitative findings above that this aspect of addressing RDA has been uneven across US public libraries.

Although not a dominant concept from a purely quantitative analytical perspective, many respondents did not see the rationale for switching wholesale from AACR2R to RDA. Commentary on this particular theme was presented as though from a cataloger's and from a patron's perspective. One respondent wrote, "I see no point in RDA until the ILS systems start using the coding. Those extra fields do nothing in Polaris," indicating that some current software technologies are not allowing RDA to deliver its full potential to OPAC users. Another respondent commented that he/she wanted "Significant proof of how it improves variables also have an impact on RDA adoption and use, including public library catalogers' highest level of education, library budgets, and the population of the community served. Some of these latter variables are often a reflection of whether the library is located in a rural or urban area, but one should not assume that this is always the case. For instance, an urban area located in the American "rust belt" may find its population declining to a threshold that comes close to a rural library service area, thus affecting this area's library budget due to declining tax revenues. However, the data also demonstrate that other factors affect rural library systems with regard to RDA adoption and implementation. Rural library systems are considerably less likely to employ catalogers with master's degrees, for instance. This difference may be simply because rural libraries are unable to hire as many master's graduates as urban libraries. Some reasons include budgetary constraints, availability of nearby MLS/ MLIS graduates, or the willingness of degreed librarians to move to a rural area. This discrepancy may be attributed to the fact that urban libraries may hire more catalogers with master's degrees due to the size of the population and collections being served. Whereas urban areas may have fewer library systems compared to rural areas as mentioned earlier (and as our data's breakdown of urban and rural library systems/libraries suggest), these urban systems are so large in terms of collections and population served (again, e.g., NYPL) that it appears reasonable to assume they would hire more catalogers. Regardless, the discrepancy in this 
particular variable (highest education attained) between rural and urban libraries should receive further research for possible solutions to reduce this discrepancy.

How might the glaring discrepancies in RDA adoption and implementation in US public libraries be addressed? Rather than singling out one particular institution such as a professional organization, LC, or library schools, perhaps the LIS discipline and profession should take responsibility writ large. Additionally, institutions such as IFLA (which was responsible for the creation of FRBR and its follow-up conceptual model, LRM), ALA, the Canadian Federation of Library Associations (CFLA), and the Chartered Institute of Library and Information Professionals (CILIP), along with the RDA Steering Committee, might want to consider contributing resources to assist libraries with the implementation of new descriptive standards such as RDA since the persons in these organizations presumably would be most expert on the topic. This suggestion is not to single out these named organizations as though they have not done their work or that they have not already provided some sort of training information. In fact, these organizations have already done a tremendous amount of work creating a descriptive standard that hopefully will sustain all libraries for the majority of the twenty-first century. However, if the people for whom this work (FRBR, LRM, and RDA) has been done are unable to perform their own professional work properly or have difficulty using the tool created for them, then one must ask if that work has been actually completed. Considering that the only constant in twenty-firstcentury librarianship is change, the authors suggest that this work is not complete, and look forward to both international and national library organizations' continued contributions to the professional development of all cataloging librarians and library technicians.

The authors hope that this discrepancy will encourage more urgent professional development discussions, particularly as their findings demonstrate that urban-rural differences as they pertain to using RDA, at this point, extend beyond the issue of cost. Based on the demographic data collected by the authors' survey, the gaps in adopting new descriptive standards exemplified by a work such as RDA appear to be based on issues beyond the control of cataloging personnel. There appears to be no lack of potential or realized intellectual capital in rural public libraries compared to their urban counterparts. Rural library staff are well educated (except for the relative lack of possession of the LIS discipline's terminal degree) and are seeking further professional development opportunities to maintain their professional practices by working with RDA. The apparent lack of financial capital that can be invested in professional development opportunities is the largest driver accounting for the discrepancy between rural and urban cataloging colleagues. As Haider found in his survey of university library catalogers, those university libraries with the most financial resources (private universities in particular) offered the greatest amount of RDA training and professional development for its catalogers. If rural public libraries want or need their catalogers to be able to effectively implement RDA, they need to allocate the funds to help their employees. With an already small tax base, and one that may shrink in the future, rural public library systems are fighting an uphill battle (although some urban areas with shrinking populations and tax bases are suffering the same fate). Although other libraries, library organizations, or individual library professionals should never be expected to support library systems financially with limited resources, these entities can give time back to the profession. For example, McCutcheon has created a YouTube video on cataloging with RDA expressly for practicing copy catalogers. ${ }^{26}$ Lambert has conducted a number of in-person presentations to regional library systems across his home state accompanied by resource materials for the audience members to take back to their respective technical services departments to assist them with working with RDA. Many other LIS professionals and academics are doing the same, as are many LIS organizations and institutions that offer free or low-cost webinars or in-person presentations. While these efforts should be lauded and encouraged, they are still haphazard and largely decentralized, with perhaps many of our cataloging colleagues missing out on excellent opportunities despite good intentions.

\section{Conclusion}

It is disconcerting that 21.6 percent of respondents stated that the first time they were aware of RDA was when they completed the authors' survey. This is a stunning educational gap and demonstrates that that we are creating a large divide in the area of RDA education and training for public library staff, particularly when compared with academic library staff. The survey data show this correlation between RDA knowledge and level of education. Economics also plays a major role, since many small, rural public libraries lack funding to purchase materials such as the RDA Toolkit for their cataloging staff, or funding for training on how to use and apply RDA.

This study shows the emergence of a major group of cataloging staff in public libraries who are being excluded from the development process of current cataloging standards. It will become even more difficult for public library catalogers to understand RDA when the theoretical structure changes from FRBR to LRM in 2018. Education and professional development can be improved for our public library catalogers, especially those who serve their communities in rural America. 


\section{References}

1. Michael Gorman, Paul W. Winkler, and American Library Association, eds., Anglo-American Cataloguing Rules, 2nd ed. (Chicago: ALA, 1978).

2. Frank P. Lambert, Roman S. Panchyshyn, and Sevim McCutcheon, "Resource Description and Access and Ohio Public Libraries," Public Library Quarterly 32, no. 3 (2013): 187-203, https://doi.org/10.1080/01616846.2013.818497.

3. IFLA Study Group on the Functional Requirements for Bibliographic Records, and International Federation of Library Associations and Institutions, eds. Functional Requirements for Bibliographic Records: Final Report. UBCIM Publications, new ser., v. 19. (München: K.G. Saur, 1998).

4. Pat Riva, Patrick Le Boeuf, and Maja Žumer, "IFLA Library Reference Model: A Conceptual Model for Bibliographic Information" (IFLA, 2017), http://www.ifla.org/files/assets /cataloguing/frbr-lrm/ifla-lrm-august-2017.pdf.

5. Elyssa M. Sanner, "Preliminary Training for RDA: A Survey of Cataloging Department Heads," Journal of Library Metadata 12, no. 2 (2012): 213-41, https://doi.org/10.1080/19386 389.2012.699845.

6. Dana Hanford, "ALookat How We Got Here: RDA Implementation at Central Connecticut State University," Journal of Library Metadata 14, no. 3-4 (2014): 152-65, https://doi.org /10.1080/19386389.2014.977725.

7. Qiang Jin and Jane A. Sandberg, "Implementing RDA at the University of Illinois at Urbana-Champaign Library," Technical Services Quarterly 31, no. 3 (2014): 217-36, https://doi .org/10.1080/07317131.2014.908585.

8. Amy H. Turner, "RDA Training and Implementation at Duke University Libraries: Minimizing the Distraction," Journal of Library Metadata 14, no. 2 (2014): 69-76, https://doi.org /10.1080/19386389.2014.909671.

9. Meghan Finch, "Using Freely Available RDA Resources to Provide In-House Training to a Medium-Sized Academic Library," Journal of Library Metadata 16, no. 2 (2016): 94-114, https://doi.org/10.1080/19386389.2016.1215736.

10. Jung-Ran Park and Yuji Tosaka, "RDA Implementation and Training Issues across United States Academic Libraries: An In-Depth E-Mail Interview Study, Journal of Education for Library \& Information Science Online 56, no. 3 (2015): 252-76, https://doi.org/10.12783/issn.2328-2967/56/3/6.

11. Salman Haider and Primary Research Group, Survey of Emerging Cataloging Practices: Use of RDA by Academic Libraries (n.p.: Primary Research Group, 2016).
12. Emma Cross etal., "In the Company of My Peers: Implementation of RDA in Canada," Cataloging \& Classification Quarterly 52, no. 6-7 (August 2014): 747-74, https://doi.org/10.10 80/01639374.2014.899535.

13. Institute of Museum and Library Services, Public Libraries Survey, accessed June 1, 2018, http://www.imls.gov /research-evaluation/data-collection/public-libraries-survey.

14. Public Library Association, PLAmetrics, accessed June 1, 2018, http://www.plametrics.org.

15. Public Library Association, PLDS Statistical Report: Characteristics and Trends, accessed June 1, 2018, http://www .plametrics.org/index.php?page_id=16.

16. Public Library Association, PLDS Statistical Report.

17. Brian Real, John Carlo Bertot, and Paul T. Jaeger, "Rural Public Libraries and Digital Inclusion: Issues and Challenges," Information Technology \& Libraries 33, no. 1 (March 2014): $6-24$.

18. Jeanne Goodrich, "Staffing Public Libraries: Are There Models or Best Practices?” Public Libraries 44, no. 5 (2005): 277-81.

19. Elizabeth S. Bliss, "Staffing in the Small Public Library: An Overview,” Rural Libraries 26, no. 1 (2006): 7-28.

20. Frances F. Stumpf, "Centralized Cataloging and Processing for Public Library Consortia," The Bottom Line, 16, no. 3 (2003): 93-99, https://doi.org/10.1108/08880450310488003.

21. OCLC, A Snapshot of Priorities and Perspectives: U.S. Library Consortia, accessed June 1, 2018, http://www.oclc .org/content/dam/oclc/reports/us-consortia/214986-member -communication-survey-report-consortia-review.pdf.

22. Christian Burris, "The User Experience and Technical Services," Technicalities 36, no. 4 (2016): 14-17.

23. United States Census Bureau, Geographic Terms and Concepts-Census Divisions and Census Regions: Census Bureau Regions and Divisions with FIPS Codes, February 9, 2015, accessed June 15, 2017, https://www2.census.gov/geo/docs /maps-data/maps/reg_div.txt.

24. United States Census Bureau, Geography: Urban and Rural, December 8, 2016, accessed February 21, 2017, http://www .census.gov/geo/reference/urban-rural.html.

25. WordClouds.com, accessed January 30, 2018, http://www .wordclouds.com.

26. Sevim McCutcheon, "Resource Description \& Access (RDA) Basics for Copy Catalogers,"YouTube Video, 54:37, September 3, 2013, http://www.youtube.com/watch?v=6IUyBaDdc8c. 